\title{
WIND TUNNEL STUDY OF GAS DISPERSION FROM GROUND SOURCE ON A SINGLE BUILDING
}

\author{
P. MICHÁLEK \& D. ZACHO \\ Department of Aerodynamics, Aerospace Research and Test Establishment (VZLU), Prague, Czech Republic.
}

\begin{abstract}
Experimental investigation of dispersion from ground source on a single building model was performed. The measurements were conducted in boundary layer wind tunnel in Aerospace Research and Test Establishment (VZLU). Simple rectangular building model, gas flow controllers and flame ionization detectors were used for these experiments. Emissions presented non-buoyant and heavy gases emitted out of a ground-level point source. Tracing gas (ethane) was used for the concentration measurements. Effect of changing source concentration and source distance was studied both on windward and leeward side of the model building. Significant differences between these two basic cases were observed.
\end{abstract}

Keywords: Emission dispersion, ground-level source, boundary layer wind tunnel.

\section{INTRODUCTION}

There has been significant development in the field of air pollution modelling, even though it is a very challenging task. The emphasis in air pollution modelling is now placed on computer modelling and simulation due to increasing computing power, but experimental measurements in wind tunnels or in situ still have their inevitable place. The so-called physical modelling techniques are mainly used for computer models validation and verification and for model comparison.

There are many industrial chemical plants in the world, which use various toxic gases and other chemical substances. These gases present a serious potential threat to the workers and neighbouring community in the case of accident or any other unfortunate event. Non-buoyant and dense gases (e.g. propane) are potentially more dangerous, because they spread and stay near the ground surface, whereas buoyant and light gases (e.g. helium and hydrogen) disperse quickly.

Experimental verification of computer simulation results will also be a part of new software, which is developed in VZLU. This software will be used for estimating the progress of gas dispersion in chosen urban areas in Czech Republic under actual meteorological conditions. The software will be based on pre-calculated results of gas dispersion in turbulent boundary layer in urban areas near chosen chemical factories considering 3D terrain model including buildings. In case of accident or terrorist attack, the size of the contaminated area with harmful gases will be estimated using this software. Standard dispersion models are time and computing power consuming, that is why our model uses pre-calculated results for the most significant weather conditions, i.e. wind direction, etc. Such a dispersion model, which would take into account topography, buildings and actual plus forecasted meteorological conditions, does not exist in the Czech Republic. The VZLU dispersion model uses Navier-Stokes equations with k-omega turbulence model and dispersion equations.

\section{SIMULATING THE WIND}

\subsection{Boundary layer wind tunnel in VZLU}

The boundary layer wind tunnel (BLWT) in VZLU was built in cooperation with Czech Technical University in Prague in 1996 (Fig. 1). The BLWT has 15.6-m long, 1.8-m wide and 1.5-m high working part and is equipped with $55 \mathrm{~kW}$ fan. Maximum wind speed above boundary layer in tun- 


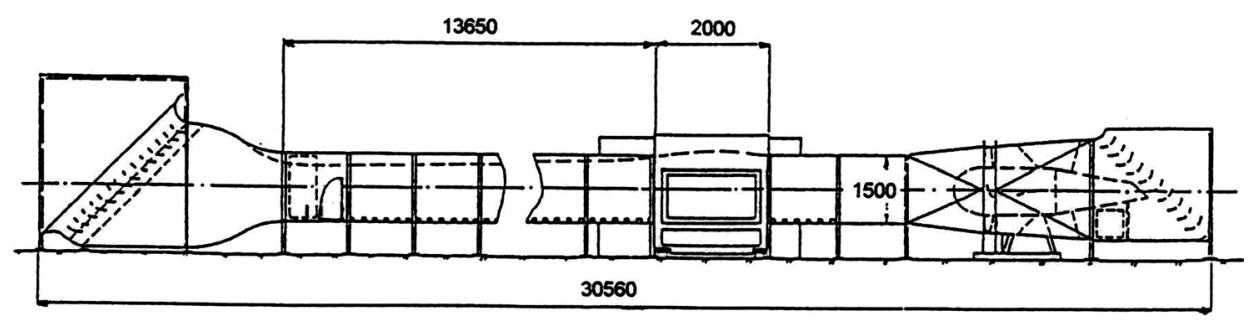

Figure 1: BLWT in VZLU Prague.

nel is $25 \mathrm{~m} / \mathrm{s}$. Instrumentation of the BLWT includes hot-wire anemometer, pressure scanner, particle image velocimeter with laser and high-speed camera, hydrocarbon tracing and detection system with flame ionization detectors and computer with analogue-to-digital input card. Probe traversing is made possible with traversing mechanism. Test section where models can be mounted is equipped with turntable $1.75 \mathrm{~m}$ in diameter. There are two independent fixed probes, i.e. Pitotstatic probe and Dantec steel clad transducer, which monitor the velocity above the boundary layer in front of the test section. Fan revolutions are controlled via digital counter and computer. Atmospheric conditions, i.e. temperature, barometric pressure and relative humidity, are measured and recorded in the computer. Pressure in the entire working section is monitored via pressure sensors.

\subsection{Boundary layer modelling}

Simulation system allows application of three boundary layer types: agricultural, suburban and urban according to Eurocode 1 [1]. Boundary layer entering test section must be fully developed, i.e. the velocity profile must correspond with the logarithmic law according to Eurocode 1 and ASCE publication No. 67 'Wind tunnel studies of buildings and structures' [2]. The logarithmic law is defined for indifferent atmospheric layering as

$$
U(z)=\frac{u^{*}}{k} \cdot \ln \left[\frac{z-d}{z_{o}}\right]
$$

where $\mathrm{u}^{*}$ is the frictional velocity (dynamic velocity) $(\mathrm{m} / \mathrm{s}), \mathrm{k}=0.4$ is the von Karman's constant, $\mathrm{z}_{0}$ is the frictional height (aerodynamic roughness) $(\mathrm{m}), \mathrm{d}$ is the zero-plane displacement, $\mathrm{U}$ is the mean velocity and $\mathrm{z}$ is the vertical coordinate.

The second condition involves overcritical Reynolds roughness number $\operatorname{Re}^{*}=\mathrm{z}_{0} \mathrm{u}^{*} / \mathrm{v} \geq 2.5$, where $v$ is the cinematic viscosity of air $\left(\mathrm{m}^{2} / \mathrm{s}\right)$. For the purpose of gas dispersion modelling, this condition can be relaxed up to Re* $\geq 1.0$ according to ASCE No. 67 [2].

The third necessary condition for modelling turbulent boundary layer is that the power spectrum of boundary layer contains the so-called 'inertial subarea', which means that part of the power spectral density agrees with the '-5/3-power slope curve'. Power spectrum for incoming boundary layer at height $300 \mathrm{~mm}$ is presented in Fig. 2.

Suburban turbulent boundary layer is created with 140-mm high rectangular barrier at the beginning of working section and with roughness field 13-m long made of plastic insulation sheet with 7-mm high truncated cones placed on the working section floor, which contributes to create fully developed turbulent boundary layer entering the model section. 


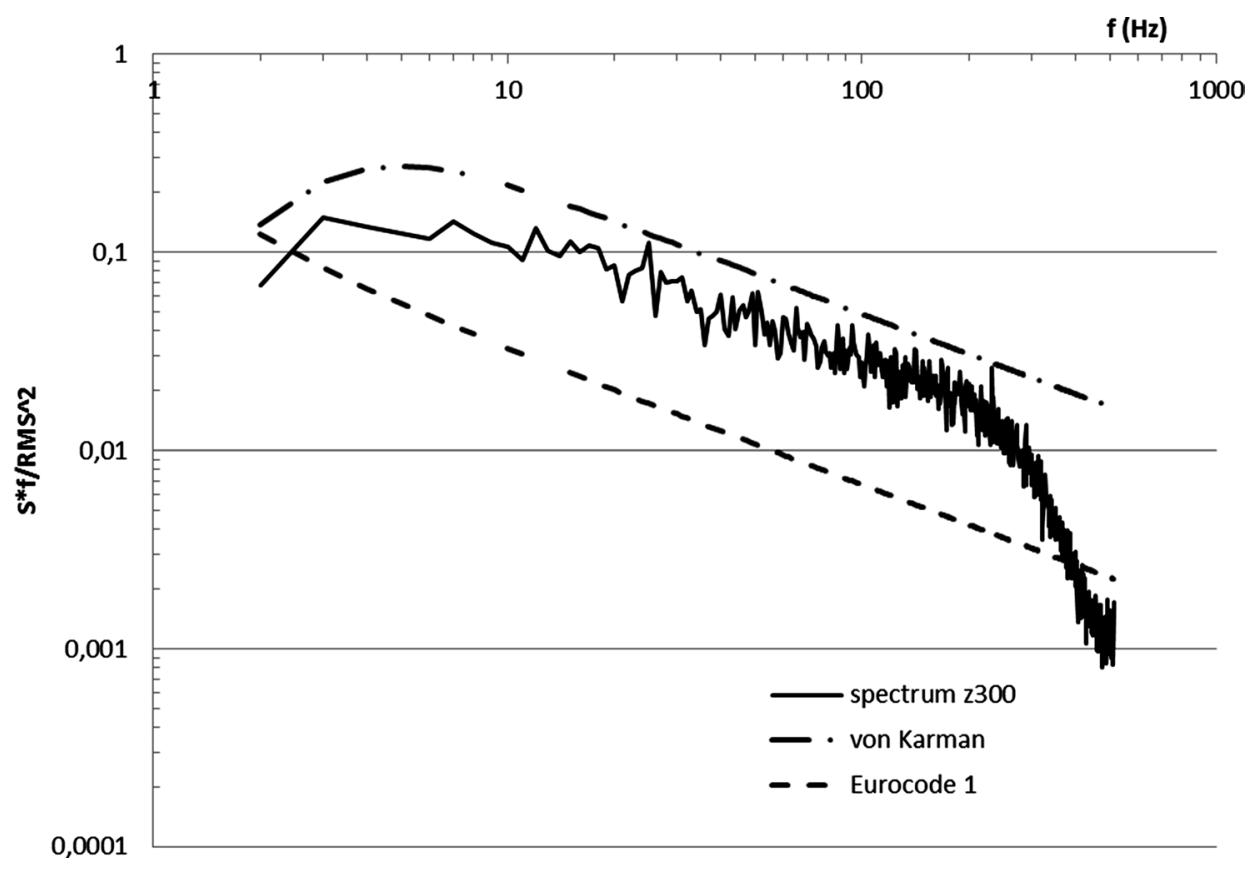

Figure 2: Power spectral density.

\subsection{Gas dispersion modelling}

The BLWT in VZLU was equipped with devices for experiments with tracer gas (ethane) in the year 2000. Since then, many experiments with tracer gas have been performed, e.g. heavy gas dispersion studies by Ulman et al. [3] and Ulman [4], pressure and concentration measurements on 3D model building for inlet and outlet optimization by Jirsak et al. [5], air infiltration into model building by Michalek and Zacho [6] and gas leakage from railway station inside urban area by Ulman et al. [7] and also simulation of chimney plumes by Jirsak and Ulman [8].

The equipment for gas dispersion modelling includes pressure vessels with gases, electronic flow controllers and tubing and emission source. Measuring devices include model with sampling taps, silica capillary tubing, peristaltic pumps and four flame ionization detectors FID-80 with electrometers EL-980, which are connected to a computer with A/D input card. The measuring principle of flame ionization detector is based on measuring electric current changes in hydrogen flame. The changes are caused by incoming sample containing hydrocarbon tracing gas - ethane. The electric signal can be recalculated into concentration according to calibration of the FIDs, which is made with mixture of gases of known concentration $100 \mathrm{ppm}$ of ethane in air.

Many dispersion studies have been made in the world; however, many of them investigated emission dispersion from stacks (chimneys) or ground line sources. Meroney et al. [9] have studied flow and dispersion from line source about some building shapes, Chavez et al. [10] have studied pollutant dispersion from stack placed on top of building, Robins et al. [11] made a wind tunnel study of dense gas dispersion from line source in neutral boundary layer, Janour et al. [12] performed wind tunnel study of dispersion from stack over an industrial site, Roberts and Fryer-Taylor [13] have investigated the roughness effects on gas dispersion using ground area source, and many others. 


\section{EXPERIMENT DESCRIPTION}

\subsection{Dispersion in the near field of the source}

The emission source was designed to simulate ground-level continuous emissions of gases from some smaller industrial chemical plants or gas tanks. This source consists of small chamber sized $30 \times 30 \times 10 \mathrm{~mm}$ whose one side of rectangular size $25 \times 25 \mathrm{~mm}$ was covered with porous fabric used in air-condition filters. The topside of the source is placed in wind tunnel floor level in the centre of the turntable. The fabric in the source top allows slowing down gas emission velocity; therefore, the emission exit velocity is much lower than the ambient flow velocity.

Two variants of tunnel floor roughness in the test section were made to make significant changes in mean velocity and turbulence intensity profiles. For smooth variant, a $2.2-\mathrm{m}$ long part of the tunnel floor upwind the emission source was provided with smooth surface. The other part of tunnel test section remained unchanged with roughness field made of plastic sheet with 7-mm high truncated cones. On the contrary, to make longer rough surface, the half of model section floor $(1 \mathrm{~m})$ upwind the source was covered with the same plastic sheet with cones, so that the roughness field made an continuous field from the beginning of test section up to the emission source in the centre of the model section. These two roughness adjustments created changes of mean velocity profiles and turbulence intensity, as seen in Fig. 3. These measurements were performed with hot-wire anemometer Dantec Streamline with single-wire probe and measured in the centre of model section in both cases. $\mathrm{U}$ stands for the mean velocity in $\mathrm{m} / \mathrm{s}$ at height $\mathrm{z}$ in $\mathrm{mm}, \mathrm{U} €$ stands for the velocity above the boundary layer and Iu means the intensity of turbulence in percent. The curves show higher mean velocities in the lower part of the boundary layer (up to $\mathrm{z}=100 \mathrm{~mm}$ ) for the smooth variant and also much higher turbulence intensity in this part for the rough variant. This proves that lower part of the boundary layer becomes accelerated on the smooth surface.

For the sake of measuring concentration field in near-field area of the source, the comb probe with four suction inlets was utilized. This comb probe was mounted on traversing mechanism. All four

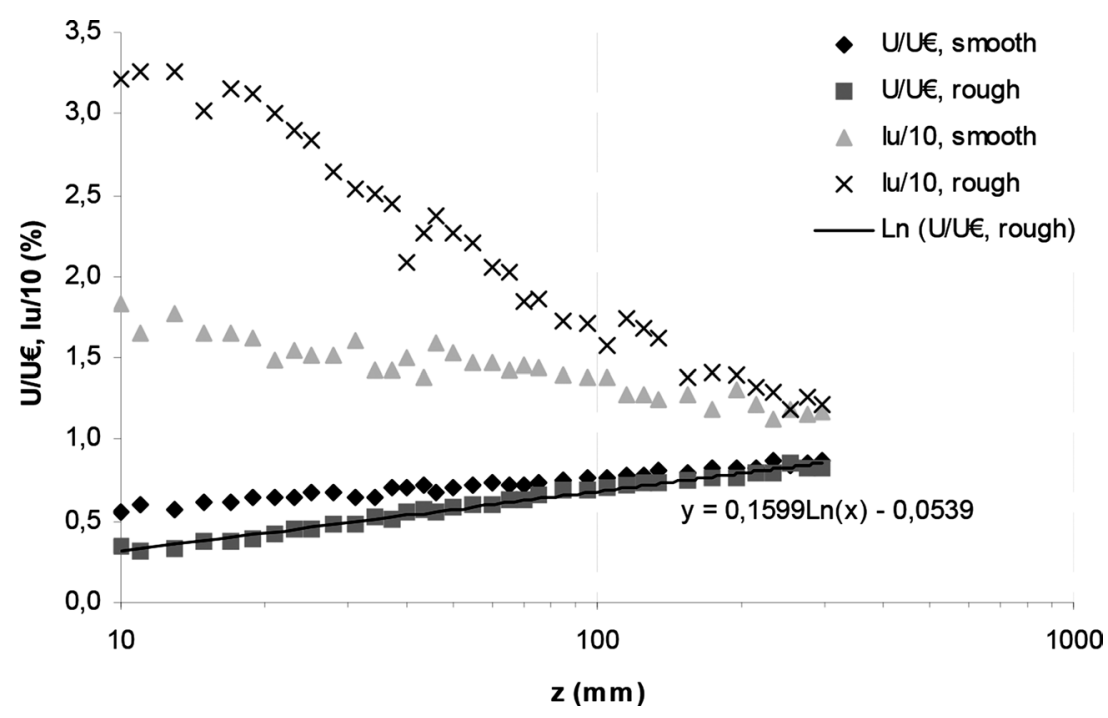

Figure 3: Vertical velocity profiles. 
individual suction inlets in the probe were spaced $10 \mathrm{~mm}$ between each other. Then the area above the source of length $32.5 \mathrm{~mm}$, width $30 \mathrm{~mm}$ and height $1-14 \mathrm{~mm}$ above the source outlet was measured. Sampling time of $60 \mathrm{~s}$ for one point and waiting time of $15 \mathrm{~s}$ for moving to next point were used. Velocity above the boundary layer was set to $4 \mathrm{~m} / \mathrm{s}$.

\subsection{Dispersion on a single building}

A simple building model with dimensions $170 \times 170 \times 60 \mathrm{~mm}$ (width $\times$ height $\times$ depth) was made of hard aluminium plates. The model was then fitted with eight sampling taps of internal diameter $1.5 \mathrm{~mm}$. The taps are located at the centreline of the model, where six of them are on the façade and two are located on the roof. For accurate location, see Fig. 4. Small numbers along the centreline denote tap distances in $\mathrm{mm}$, where bigger numbers are tap positions. The taps are connected via silica capillary tubing going through the internal volume of the model and then behind the model on the wind tunnel floor to the FIDs. Measuring on both windward and leeward sides of the model is made possible by simply rotating the model in $180^{\circ}$ so that the façade with taps is located on windward or leeward side.

The gases, namely air or sulphur hexafluoride $\left(\mathrm{SF}_{6}\right)$ and ethane, were dosaged using electronic flow controllers Alicat Scientific. $\mathrm{SF}_{6}$ is non-toxic and non-flammable gas with density 5.1 times bigger than air at normal conditions. It is used mainly as insulation gas in high-voltage devices. Then, the gases were mixed together and released into tube leading to the point source in wind tunnel floor. Volume flow of air or $\mathrm{SF}_{6}$ was set to $1.3-3.0 \mathrm{l} / \mathrm{min}$, ethane flow was set to $0-2.5 \mathrm{l} / \mathrm{min}$ in steps of $0.25 \mathrm{l} / \mathrm{min}$ to study the influence of increasing ethane concentration on the dispersion process. FID calibration was performed with calibration gas of known concentration (100 ppm; parts per million)

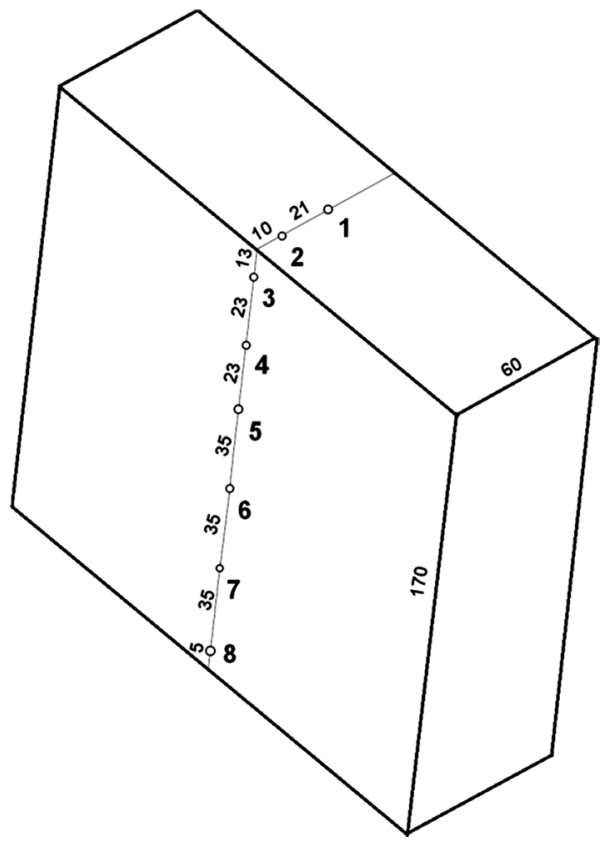

Figure 4: Scheme of sampling taps location. 


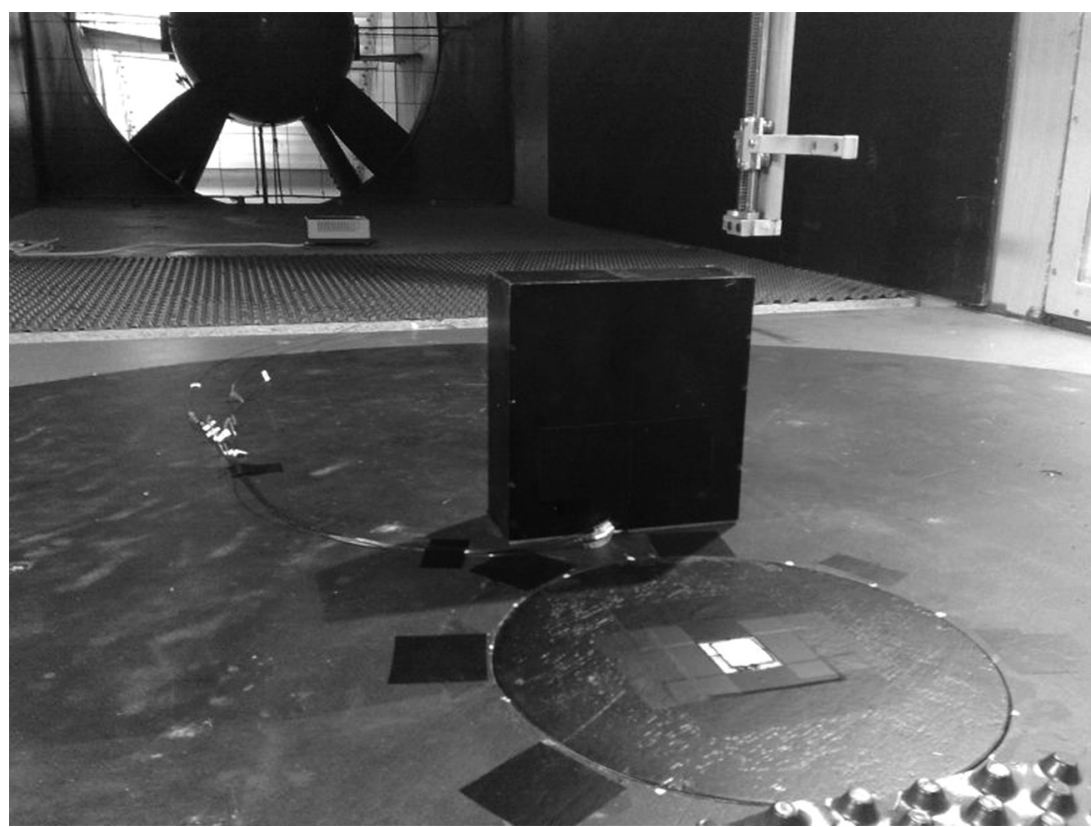

Figure 5: Model building and source in wind tunnel.

of ethane in air. The frequency response of this measuring chain is maximum at $10 \mathrm{~Hz}$, the sampling frequency was set to $100 \mathrm{~Hz}$ and measuring time for one point was $60 \mathrm{~s}$. Two basic gas mixtures were used, namely air with ethane for modelling neutral buoyant emission and $\mathrm{SF}_{6}$ with ethane for dense emission modelling. To create different emission momentum, different volume flows of air or $\mathrm{SF}_{6}$ were used. Less air or $\mathrm{SF}_{6}$ volume flux with the same ethane flux causes bigger ethane concentration and smaller emission momentum, and vice versa. $\mathrm{SF}_{6}$, thanks to bigger density than air, has bigger momentum than air within the same volume flux.

Model building with taps on leeward side installed in wind tunnel is shown in Fig. 5.

\section{RESULTS AND DISCUSSION}

\subsection{Near field of ground source}

Data analysis and graphic workspace software Origin 8 were used for displaying measured results and creating graphs. Tracer gas concentrations were recalculated into dimensionless concentration $\mathrm{C} / \mathrm{C}_{0}$, where $\mathrm{C}_{0}$ was the initial concentration of tracer gas entering the source via plastic tube. Vertical ( $\underline{\mathrm{XZ}}$ plane) concentration contour graphs for neutral-buoyant (air) gas dispersion from the source for rough (Fig. 6) and smooth (Fig. 7) variants of wind tunnel floor are presented. Source is located at coordinates $(0,0)$ and wind direction is from right to left. It can be observed in Figs 6 and 7 that the plume has spread higher in the rough variant of tunnel surface, which has greater turbulence intensity. For dispersion of dense gas containing $\mathrm{SF}_{6}$, see the conference paper Michalek and Zacho [14]. 


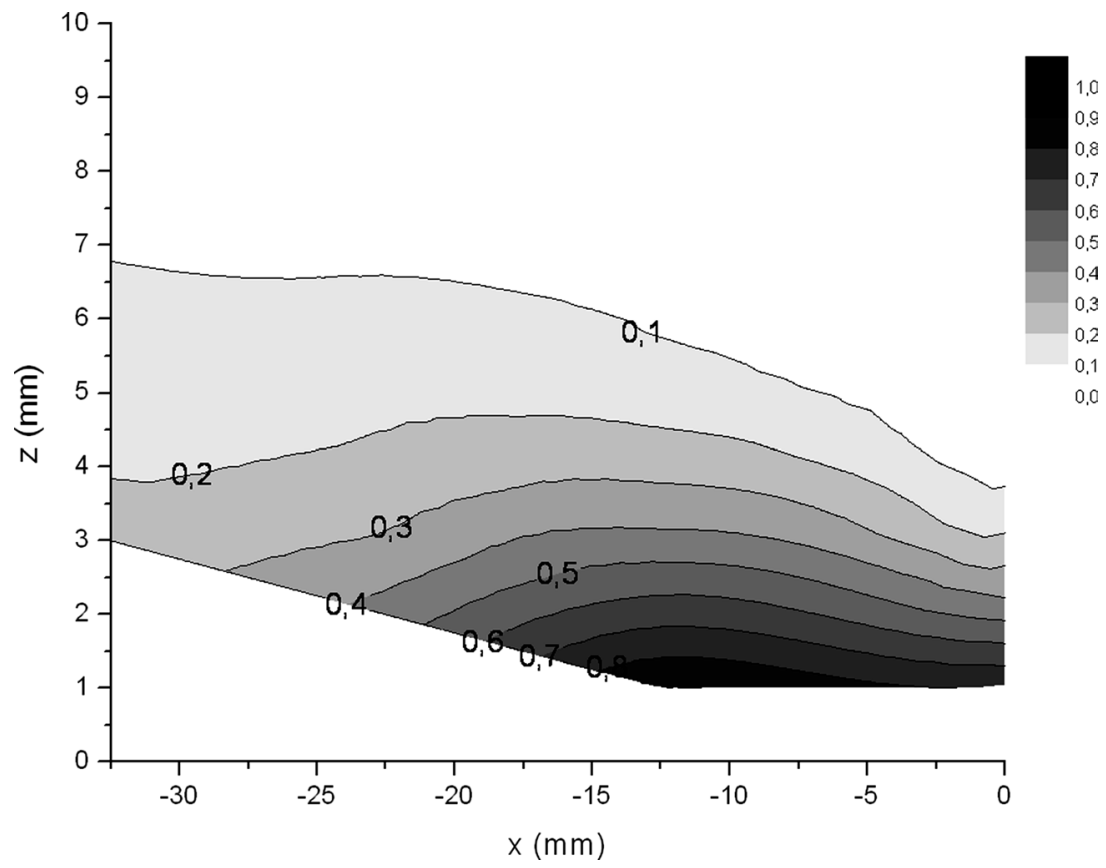

Figure 6: Neutral gas dispersion on rough surface.

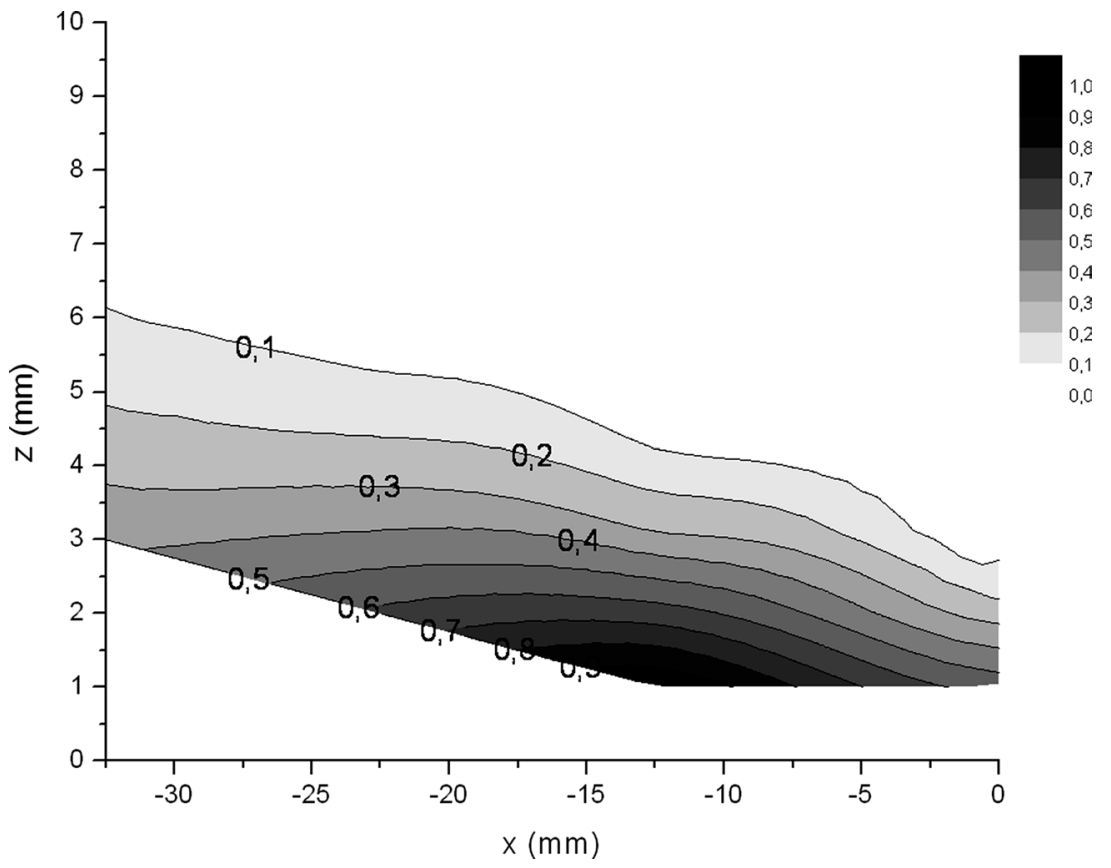

Figure 7: Neutral gas dispersion on smooth surface. 


\subsection{Dispersion on building model}

The process of dispersion of both neutral and dense gases was studied on a simple building model. The effect of façade orientation, i.e. windward or leeward position against the incoming wind and effect of emission buoyancy, i.e. neutral (non-buoyant air) or dense gas was studied. The model was located downwind to source at distance $1 \mathrm{H}$, where $\mathrm{H}$ is the height of the model $(170 \mathrm{~mm})$.

The effect of building orientation on both neutral and dense gas dispersion was investigated; therefore, the façade with sampling taps was oriented first on windward side of the incoming boundary layer and then the model was rotated in $180^{\circ}$ so that the model façade would appear on the leeward side. To study the effect of increasing ethane concentration, released from ground source, the measurements were commenced with zero ethane release (only air or $\mathrm{SF}_{6}$ was released into wind tunnel) and the amount of ethane was increased in steps of $0.25 \mathrm{l} / \mathrm{min}$. The background ethane concentration in wind tunnel was also monitored on the tunnel wall at height $0.5 \mathrm{~m}$ above the tunnel floor. The measurements showed that the background ethane concentration did not nearly increase at all, probably because of the open-circuit wind tunnel.

Measured concentrations in ppm were recalculated into non-dimensional values $C / C_{0}$, where $C_{0}$ was calculated as the concentration of ethane in air or in SF6 in ppm emitted from the ground-level source. Position of the sampling taps was expressed in fraction $\mathrm{z} / \mathrm{H}$, where $\mathrm{z}$ is the height of the sampling tap above tunnel floor and $\mathrm{H}$ is the model building height. Tap No. 1 and 2 located on the roof have the value of $\mathrm{z}=\mathrm{H}+31 \mathrm{~mm}(\mathrm{z} / \mathrm{H}=1.18)$ and $\mathrm{z}=\mathrm{H}+10 \mathrm{~mm}(\mathrm{z} / \mathrm{H}=1.06)$. The first point in graphs with value of $\mathrm{z} / \mathrm{H}=0$ is the background ethane concentration, which was measured on tunnel side wall at height approximately $0.5 \mathrm{~m}$. Ergo the tap numbers on graphs on horizontal axis are from left to right: background, tap no. 8-1.

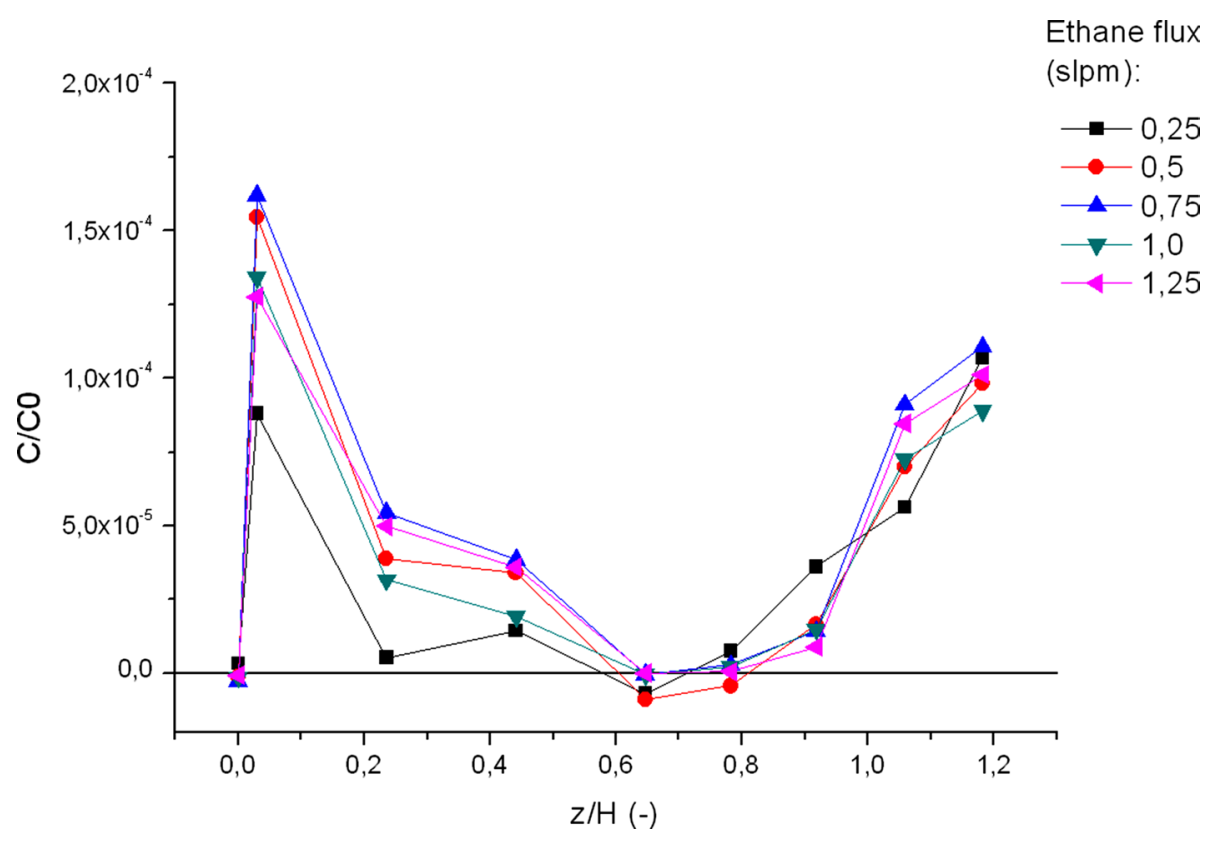

Figure 8: Concentration on windward side, neutral emission. 
Figures 8 and 9 show the relative concentration on windward and leeward sides with neutral emission (air) - air flux $1.3 \mathrm{l} / \mathrm{min}$ and increasing ethane flux in emission. Figures 10 and 11 show the relative concentration on windward and leeward sides with dense emission - SF6 flux 1.3 1/min and increasing ethane flux in emission. Figures indicate that the windward concentration reaches its maximum values near ground and on the roof. In higher parts of the façade, the concentration decreases down to the value of ambient background concentration. This might be due to the downwash effect, which means flow along the façade heading to the ground caused by the presence of high rise building. On the contrary, on the leeward side the concentration is relatively high on entire facade and on the roof, decreasing slowly with increasing height. This might be the effect of high turbulence in the wake of the building. No significant differences between neutral and dense emission can be seen, although concentration in dense emission case is a bit lower than in neutral emission case. Negative values of concentration should be considered as zero; these values occur probably due to the limited accuracy of calibration and measuring.

Figures 12-15 present relative concentrations on windward and leeward sides too, but with higher emission momentum. The same effects as in cases with lower momentum can be observed here, i.e. low concentration in higher part of the façade on windward side and higher concentration on leeward side decreasing with increasing height. However, more significant differences between neutral and dense emission can be observed here. Maximum concentration in neutral emission case is almost twice as big as in dense emission case both on windward and leeward sides. This indicates the effect of dense gas emitted near the ground, which disperses closer to the ground than gas with neutral buoyancy.

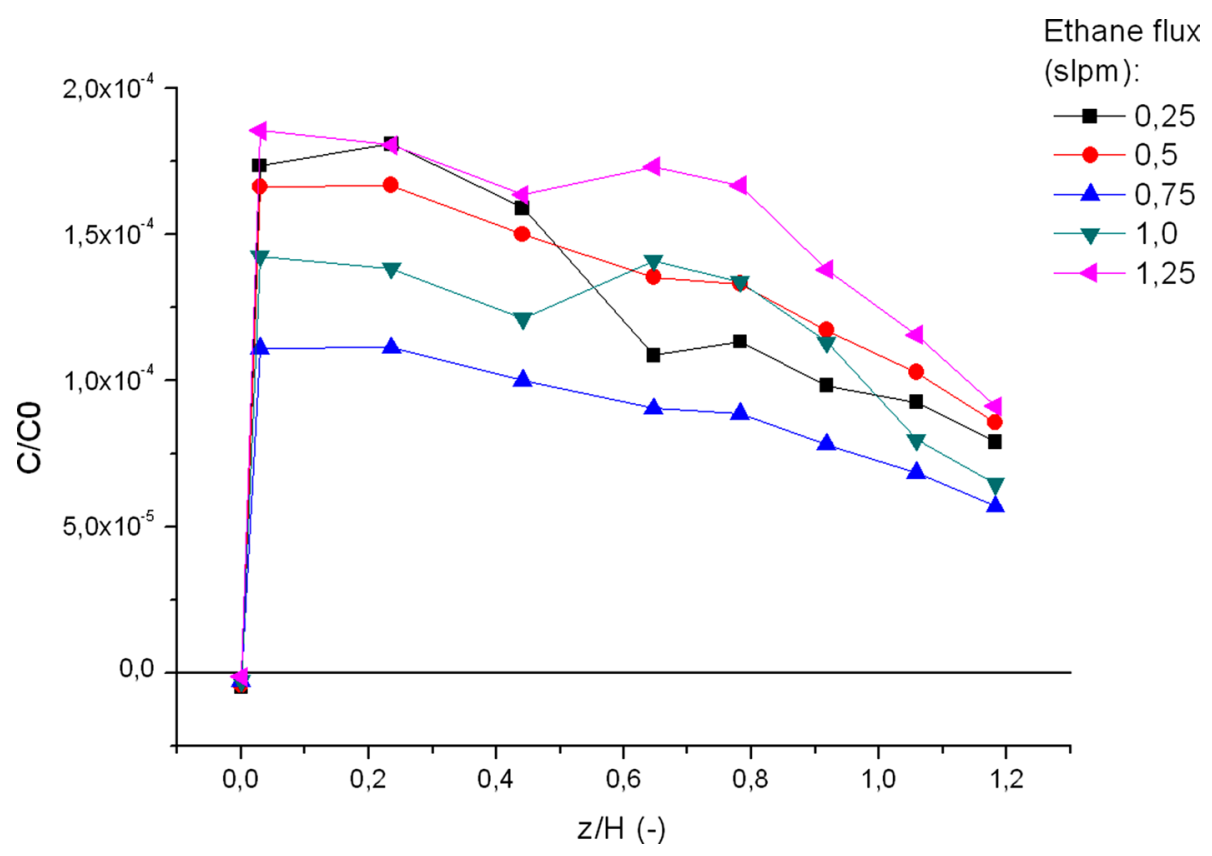

Figure 9: Concentration on leeward side, neutral emission. 


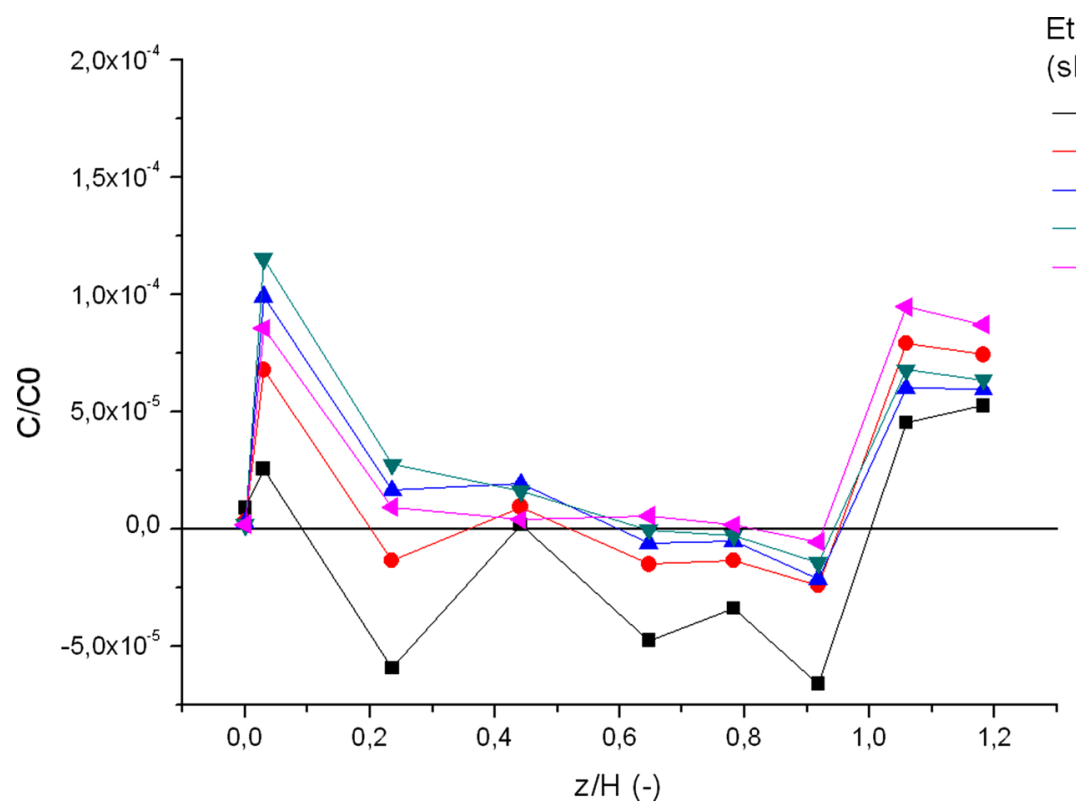

Figure 10: Concentration on windward side, dense emission.

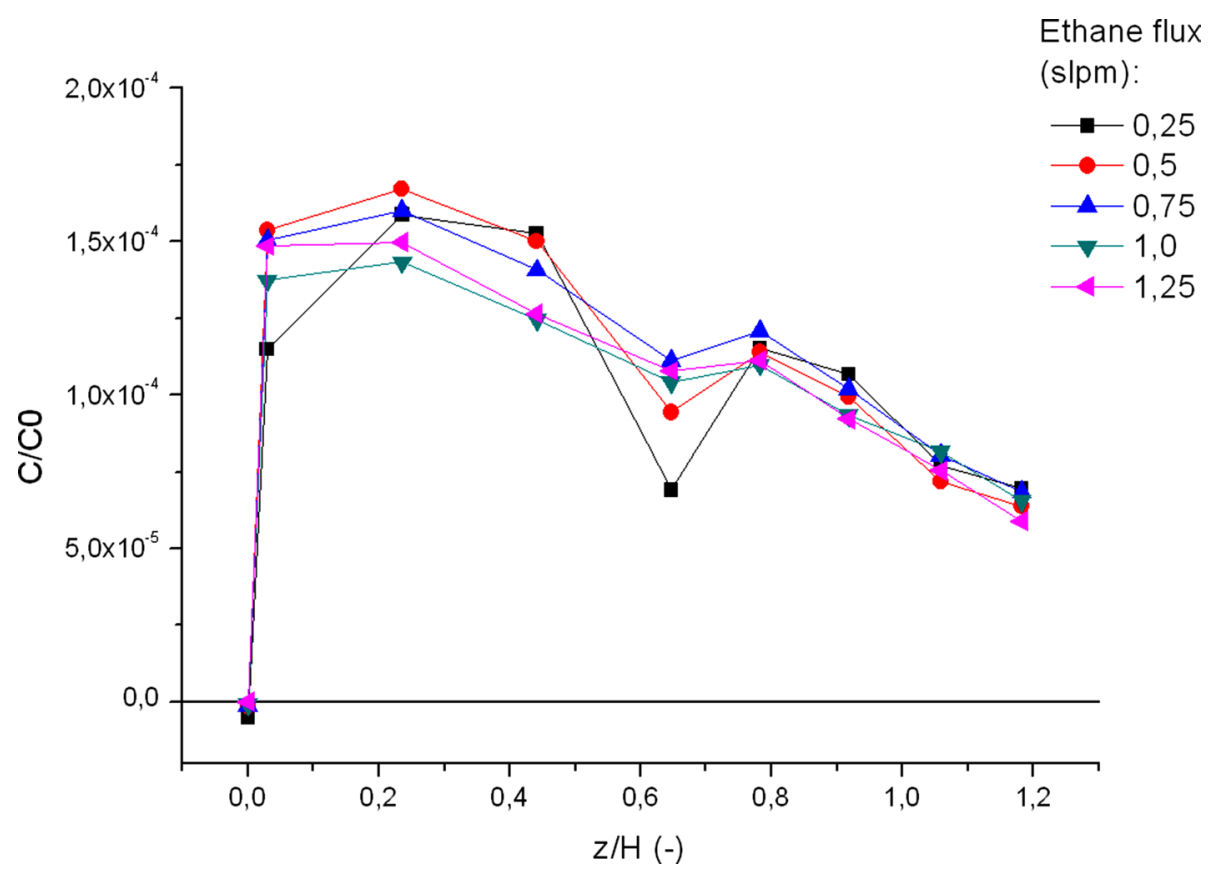

Figure 11: Concentration on leeward side, dense emission. 


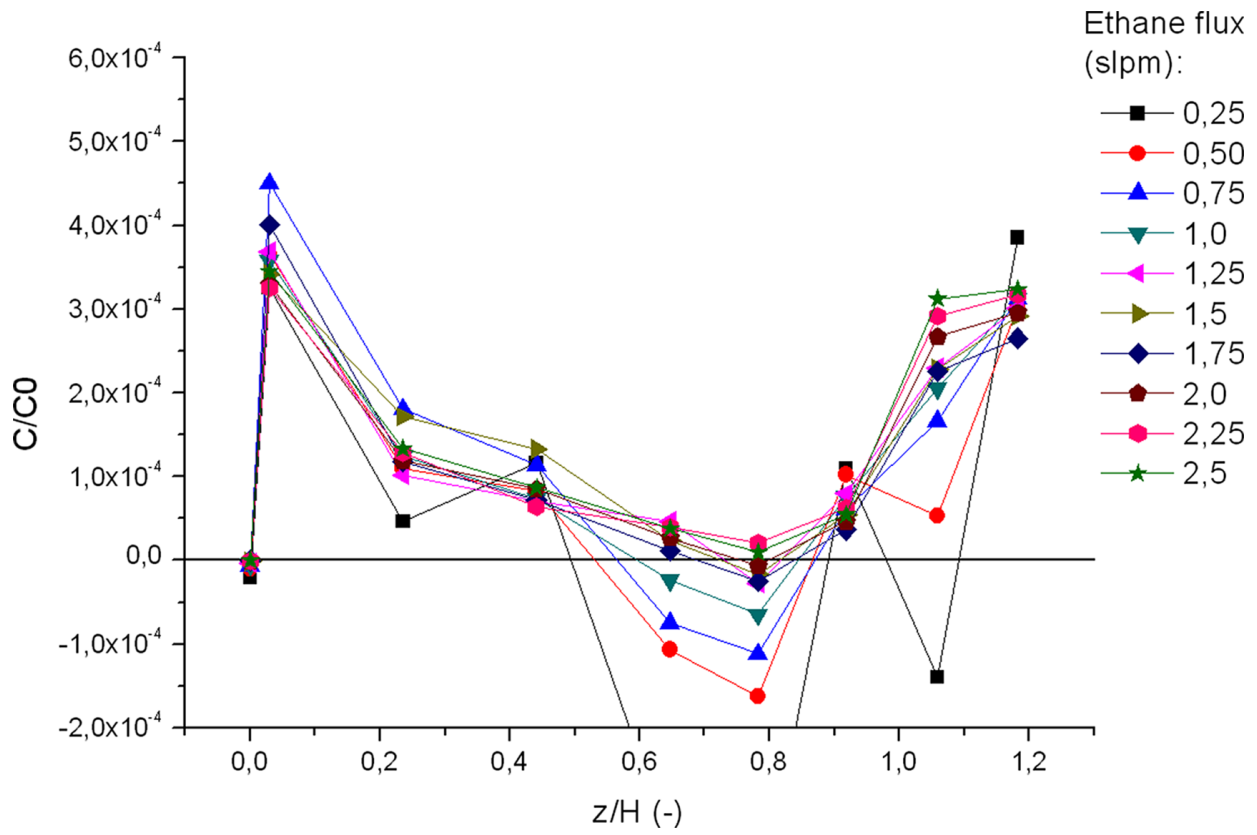

Figure 12: Concentration on windward side, neutral emission with higher momentum.

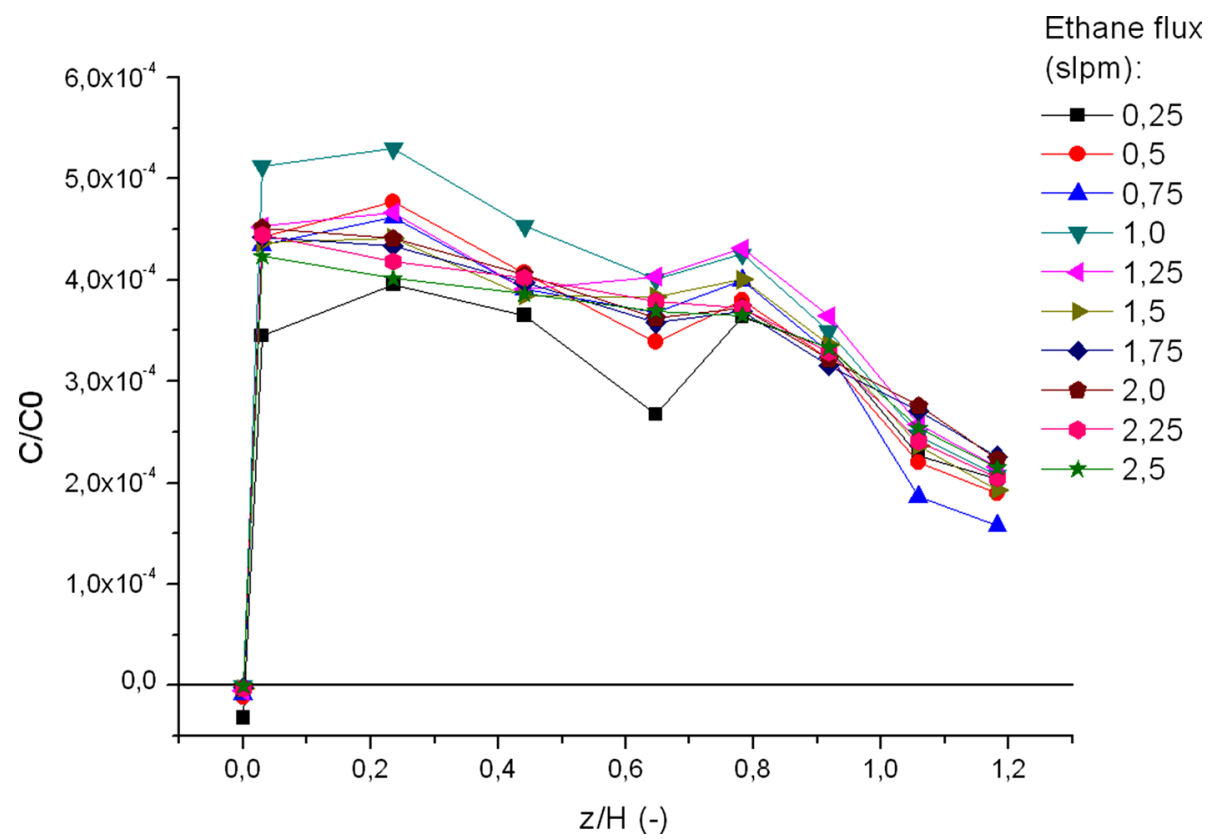

Figure 13: Concentration on leeward side, neutral emission with higher momentum. 


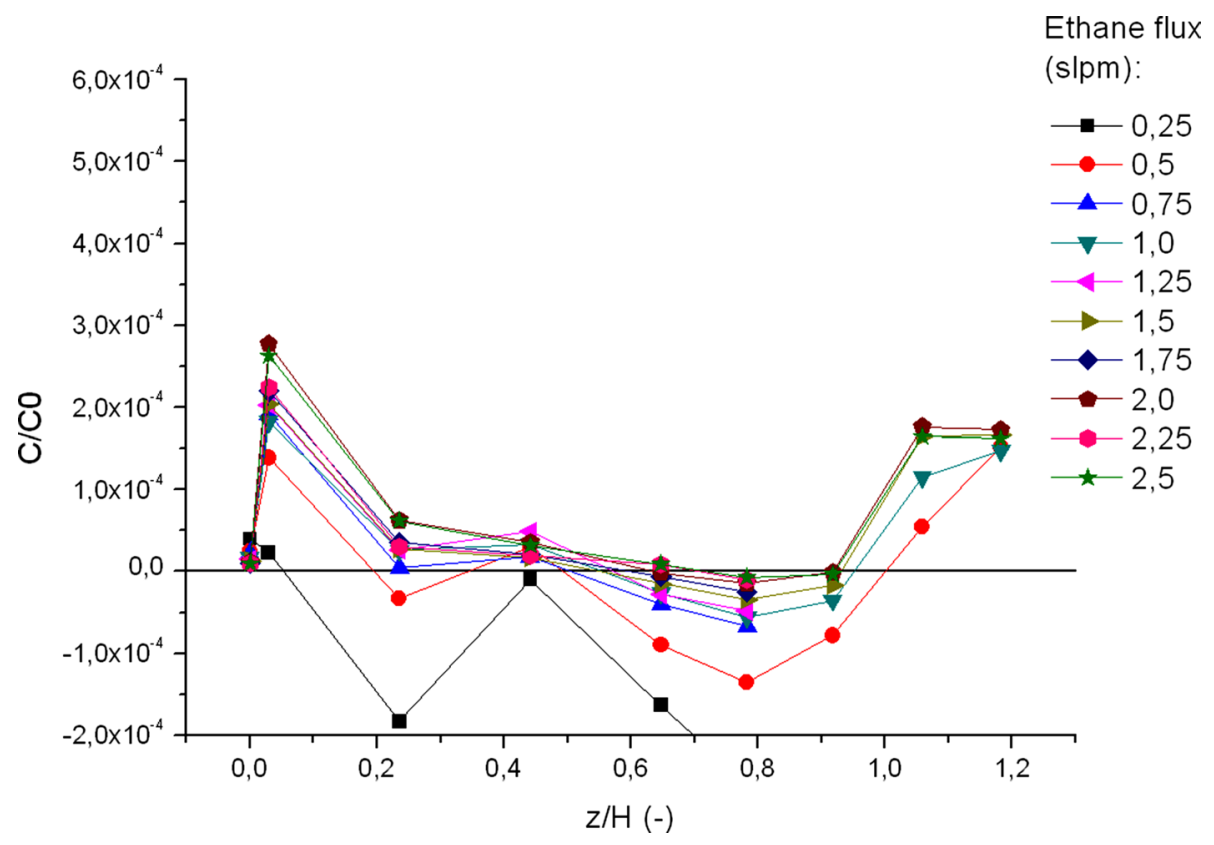

Figure 14: Concentration on windward side, dense emission with higher momentum.

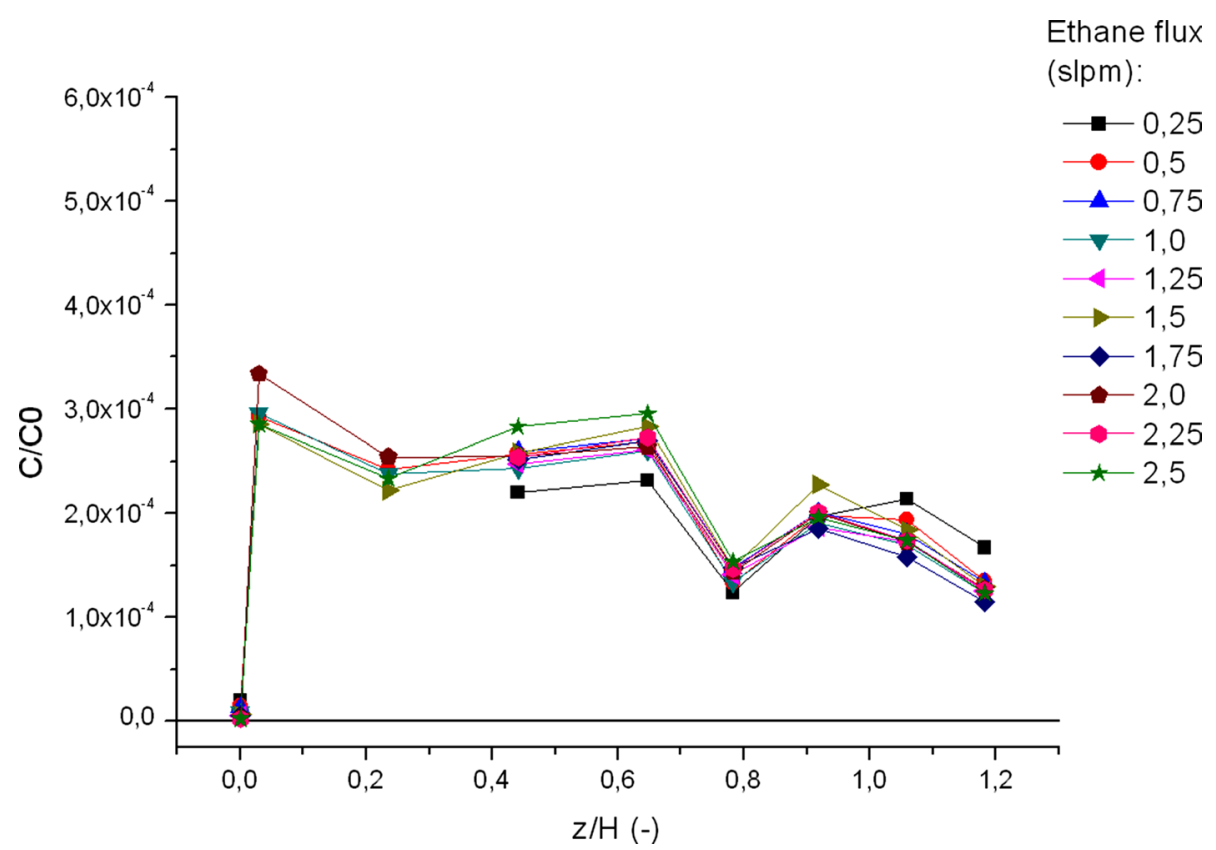

Figure 15: Concentration on leeward side, dense emission with higher momentum. 


\section{CONCLUSIONS}

The effect of neutral and dense gas dispersion in the near field of ground source and on windward and leeward sides of building model was studied. Influence of tracer gas concentration in initial emission from ground-level source on measured concentration was studied.

Dispersion in near field of ground source shows the effect of gas density (neutral or dense) and momentum. It was found that higher turbulence intensity due to rough tunnel floor caused the emission to spread higher, but dense gas was dispersing lower than neutral gas in the rough case.

Results indicate that gas dispersion on windward side is different from that on leeward side, i.e. windward side concentration on higher part of the façade is lower than the one on lower façade. However, high concentration remains still on lower parts of the façade on both sides near the ground and on the roof. There is also a difference between dense and neutral gas emission, but only in the case of higher emission momentum. All these results show that the most dangerous area for people in case of near-ground level emission is naturally the ground-level area near a building. However, the effect of more buildings can influence concentration significantly, e.g. due to the Venturi effect. The case of more buildings will be studied in the future.

\section{ACKNOWLEDGEMENTS}

This work was supported by a research programme 'SCENT', granted to VZLU by the Ministry of the Interior of the Czech Republic. The authors also thank Mr. Ruzicka for manufacturing the model with sampling taps.

\section{REFERENCES}

[1] Eurocode 1: Action on structures - Part 1-4: General actions - Wind loads (EN 1991-1-4). doi: http://dx.doi.org/10.1680/dgte1.31524

[2] Wind tunnel studies of buildings and structures, ASCE manuals and reports on engineering practice No. 67, ed. N. Isyumov, Virginia, 1999.

[3] Ulman, R., Drbohlav, J. \& Zachoval, D., Dispersion of harmful gas inside urban area. Proceedings of 7th UK Conference on Wind Engineering, eds. I. Taylor \& M. Vezza, Glasgow, pp. 201-204, 2006.

[4] Ulman, R., Physical modeling of heavy gas dispersion inside urban area. VZLU report Nr. $R$-4837, Prague, 2010.

[5] Jirsak, M. et al., Tlaková a koncentrační měření na modelu 3D budovy k optimalizaci umístění vstupů a výstupů (in Czech). VZLU report Nr. R-4029, Prague, 2006.

[6] Michalek, P. \& Zacho, D., Měření nízkých infiltračních průtoků na 3D modelu budovy (in Czech). VZLU report Nr. R-4846, Prague, 2010.

[7] Ulman, R., Janour, Z., Sedenkova, H. \& Drbohlav, J., The physical modeling of gas dispersion in topographically complicated terrain. Proceedings of EACWE4, eds. J. Náprstek \& C. Fischer, Paper No.189, Prague, 2005.

[8] Jirsak, M. \& Ulman, R., Chimney plumes simulation in the boundary layer wind tunnel. Advances in Air Pollution Series XI, WIT Press: Southampton, 2003.

[9] Meroney, R.N., Leitl, B.M., Rafailidis, S. \& Schatzmann, M., Wind-tunnel and numerical modeling of flow and dispersion about several building shapes. Journal of Wind Engineering and Industrial Aerodynamics, 81, pp. 333-345, 1999. doi: http://dx.doi.org/10.1016/s0167$\underline{6105(99) 00028-8}$ 
[10] Chavez, M., Hajra, B., Stathopoulos, T. \& Bahloul, A., Near-field pollutant dispersion in the built environment by CFD and wind tunnel simulations. Journal of Wind Engineering and Industrial Aerodynamics, 99, pp. 330-339, 2011. doi: http://dx.doi.org/10.1016/j.jweia.2011.01.003

[11] Robins, A., Castro, I., Hayden, P., Steggel, N., Contini, D. \& Heist D., A wind tunnel study of dense gas dispersion in a neutral boundary layer over a rough surface. Atmospheric Environment, 35, pp. 2243-2252, 2001. doi: http://dx.doi.org/10.1016/s1352-2310(01)00072-3

[12] Janour, Z., Jurcakova, K., Brych, K., Dittrt, F. \& Dittrich F., Potential risks at an industrial site: a wind tunnel study. Process Safety and Environmental Protection, 88, pp. 185-190, 2010. doi: http://dx.doi.org/10.1016/j.psep.2010.01.003

[13] Roberts, P.T. \& Fryer-Taylor, R.E.J., Wind-tunnel studies of roughness effects in gas dispersion. Atmospheric Environment, 28(11), pp. 1861-1870, 1994. doi: http://dx.doi.org/10.1016/13522310(94)90325-5

[14] Michalek, P. \& Zacho, D., Effect of surface roughness on neutral and dense gas dispersion in the BLWT. Air Pollution XX, Ecology and the Environment, volume 157, Paper DOI: 10.2495/ AIR120111. doi: http://dx.doi.org/10.2495/air120111 